\title{
Hospital Dentistry: Dentist's Performance in the Pediatric Sector
}

\author{
Alexandre Ramos Braga* \\ Degree in Dentistry, Specialist in Orthodontics, Specialist in Collective Health and \\ Specialist in Occupational Dentistry, Brazil \\ *Corresponding Author: Alexandre Ramos Braga, Degree in Dentistry, Special- \\ ist in Orthodontics, Specialist in Collective Health and Specialist in Occupational \\ Dentistry, Brazil. \\ DOI: $10.31080 /$ ASDS.2020.04.0976
}

Received: October 29, 2020

Published: November 09, 2020

(C) All rights are reserved by Alexandre

Ramos Braga.

\begin{abstract}
Hospital Dentistry is a dental specialty that aims to perform oral care and procedures in the hospital environment. Child hospitalization is considered a traumatic experience that leads the child to different feelings, such as anguish, anxiety and fear. The child will have to deal with different and noisy environments, lights, constant routine procedures, exposing him to great stress. The dentist's role in this context becomes very important, being part of the multidisciplinary team. The dentist, in the condition of examining children in a hospital environment, verifies the real need and the best opportunity to intervene in the oral cavity in order to maintain their healthy clinical condition as a whole. General health may be at risk if oral health is compromised, which can interfere with the recovery process. Treatment should include all dental specialties, considering a patient's clinical condition. The patient can be submitted to emergency procedures in the case of trauma and preventive procedures when the systemic condition worsens or is not affected by hospital infection.
\end{abstract}

Keywords: Hospital Dentistry; Dentist's Performance; Pediatric Sector

\section{Introduction}

The advancement of Hospital Dentistry and the introduction of the dentist in the multidisciplinary team in a hospital environment means that the professional has to be prepared to act and know the systemic and oral cavity alterations caused by certain diseases. In addition to the hygiene protocols and performance in improving the quality of life of the patient in the hospital environment, it is fundamental to know about the peculiarities of age groups.

Child hospitalization is considered a traumatic experience that leads the child to various feelings such as anguish, anxiety and fear. The child will have to deal with differentiated environments and a lot of noise, lights, constant routine procedures, exposing it to great stress. The sociability of the child decreases and this leads to a decrease in communication with the environment, causing insta- bility of behaviors. The team needs to know the case in depth for the conduct $i$ on the treatment, since children have different behaviors at each stage of life.

Sousa., et al. [1] report that child hospitalization is a stressful event and traumatizing for the child, because there is a break with his social environment, customs and habits and are conditioned to an environment full of new routines with people who are not part of their conviviality and often being subjected to procedures of pain and fear.

\section{Objective of the Study}

The objective of this work is to make a bibliographic review on the performance of the dentist in the hospital environment in the pediatric sector. 


\section{Literature Review}

According to the Code of Dental Ethics, it is up to the dentist, specialized in Hospital Dentistry, hospital is admitted and assisting patients in hospitals public and private, with or without philanthropic character, respecting the technical administrative standards of the institutions.

Elias [2] stressed the fact that the hospital is an unknown environment for child, being a place, often, of loneliness, of sadness, of longing for family members and colleagues. The family also goes through various feelings, such as guilt and loss. That is why the family also deserves attention from the entire multidisciplinary team. Integrated and humanized care, including the patient's family, interferes positive way in treatment.

Barros and Victoria [3] state that inpatient situations are seen in ways several by children. Some see this process as something painful and that causes almost uncontrollable stress, while others continue active exploration of a new environment. Therefore, the professional has to be prepared to detect such situations and to conduct the situation as best as possible.

According to Vasques, Bousso and Mendes-Castillo [4] the hospitalized child goes through various sufferings beyond the discomfort of the disease itself, such as separation, constant manipulation and pain, which generates a psychological, affective and emotional problems. It is important that professionals recognize these feelings. Therefore, it is essential to listen to the child and specify the extent of the disease process in your life.

In Latin American countries, the experience begins at graduation, and students begin the experience in the hospital still in college. In Brazil, the presence of the dentist is law since 2013 (Bill in 2,776/2008), also providing for the presence of dentists in intensive care units. However, it is not part of the training Brazilian university to train to work in hospitals, which is already a reality other Latin American countries. Brazilian surgical centers and ICUs have dentists who specialize in bucomaxillofacial surgery, as these professionals receive training to work in surgical centers.

Premature birth is a cause of the appearance of enamel defects (DDE), temporary or permanent changes in the morphology of the palate, dental occlusion, dimensions of the dental crown and the delay of tooth eruption. Ameloblasts are sensitive cells and any systemic or local stimulation may disrupt their function temporarily and respond with defects in enamel, which justifies the fact that the tooth be known as a "biological chimography".

Dickerman [5] reported that the number of child cancer survivors will continue increase and that $75 \%$ will present some chronic problem resulting from the treatment Cancer. With the increase in the patient's life expectancy, the effects caused on the oral cavity by cancer treatment become increasingly significant. The oral cavity of children on antineoplastic therapy is often affected, which generates the need for the dentist's familiarization with its consequences.

The multidisciplinary team must have the knowledge and dexterity to know how to deal with the child's complaints, conducting treatment with affection and patience. The child has rights that must be respected, such as playing, to receive visitors, to have companions and to minimize as much as possible the painful procedures. Parents and/or guardians should be part of the process, always aware of the diagnosis and treatment to which the child will be submitted. The family must also be assisted so that it can adapt to the new condition and be able to help the child in the treatment process.

The dentist, in the condition of examining children in a hospital setting, should verify the real need and the best opportunity to intervene in the oral cavity with to maintain their healthy clinical status as a whole. General health may be at risk if oral health is compromised, which may interfere with the process of recovery. The treatment should cover all dental specialties, considering the patient's clinical condition. The patient may be submitted to emergency procedures in the case of trauma and preventive procedures when worsening of the systemic condition or in the involvement of hospital infection.

Dental plaque is a complex and dynamic biofilm associated with aerobic bacteria, anaerobic and filamentous microorganisms wrapped in an extracellular matrix that covers the sub and supragingival surface of the teeth, oral mucosa and prostheses. Lotufo (2004) pointed out that the mouth also undergoes continuous col- 
onization, presenting a vast microbiota. In it, there is almost half of the microbiota present in the human body, represented by various species of bacteria, fungi and viruses.

Within the hospital complex, the dentist who works in the Maternity can work in several scenarios:

- Education of pregnant women stratified at high risk on the importance of dental prenatal care in the prevention of oral and dental changes systemic benefits, benefits of exclusive breastfeeding, changes in eating habits, oral hygiene guidelines, as well as like the outpatient dental care itself.

- Maternal follow-up in order to assist skin contact the skin (creation of affective bond between the mother and the baby). Stimulate immediate sucking, emphasizing the importance of breastfeeding Exclusive.

- The presence of the dentist in the immediate pre- and postpartum period is essential for the formation of the professional-individual bond, since, immediately after birth, the professional can assist in the identification of oral reflexes and, consequently, breastfeeding.

- $\quad$ Screening for the diagnosis of oral alterations, performance of the (TL), lingual frenulum surgery (phrenotomy) and conduction in the management of the correct handle for breastfeeding, aiming at the prevention of mamamminu fissures and early weaning.

- In the middle puerperium, i.e. in bed, the extra physical examination is performed and intraoral diseases of the NB, aiming to diagnose mainly and insertion of the lingual frenulum, which may influence the effective breastfeeding.

- $\quad$-Scheduled dental evaluations and follow-up of the newborn up to the age group of two years of age, aiming, above all, to oral health promotion.

- The outpatient clinic, as an integral part of the Multiprofessional Residency in Neonatology, focuses its actions on primary care in oral health and seeks to expand the care of babies born in the hospital, being follow-up performed up to 24 months of age.
- Oral hygiene protocols, via bundle, to reduce the rates of ventilator-associated pneumonia (VAP), diagnosis of abnormalities of the stomatognathic system and aid in breastfeeding Breast.

\section{Discussion}

Rabelo, Queiroz and Santos [6] reported that despite the importance of with oral hygiene in ICU patients, systematic studies and reviews show that such a practice is still small. The presence of infectious foci in the mouth may influence medical therapies due to the virulence factors of the microorganisms in it, which may be aggravated by the presence of other oral alterations, such as periodontal disease, caries, pulp necrosis, fractured or infected teeth and trauma caused by fixed or that can bring to the patient repercussions on their systemic condition. To these conditions are properly addressed, it is necessary to have a dental surgeon in the hospital environment, as support in the diagnosis of changes in oral and as an adjunct in medical therapy. This professional will work in emergency procedures in the face of trauma, in preventive procedures regarding worsening of the systemic condition or the emergence of a hospital infection, in curative and restorative procedures, in the adequacy of the oral environment and seeking a greater patient comfort.

Health education should be incorporated into the treatment philosophy for better quality of life of patients. The importance of dentistry is recognized in these days in places where there are hospitalized patients, both to play the role of health educator of their families, as well as to perform clinical evaluation of the factors considered at risk.

The factors considered at risk in an hospitalized patient may be: presence of oral biofilm, periodontal disease, caries, oral lesions precursor to infections viral and fungal disorders, traumatic injuries, among other injuries that can cause discomfort and worsening of the patient's condition. The hospital must have a team trained and trained to promote hygiene practices among hospitalized patients in order to improve the quality of life of these people.

In the case of the child, an appropriate protocol should be indicated for each situation, to resolve emergencies, foci of infection and pain. Then the preventive step should be implemented, when oral health guidelines are made, diet guidance and topical applica- 
tion of fluoride. The preservation of the dental structure should be a priority through the adequacy of the oral environment, removal of carious tissue with the use of hand instruments and of provisional or definitive cement. The glass ionomer should be the material of choice to complete the activities.

Dental plaque is a complex and dynamic biofilm associated with aerobic bacteria, anaerobic and filamentous microorganisms wrapped in an extracellular matrix that covers the sub and supragingival surface of the teeth, oral mucosa and prostheses. Lotufo (2004) pointed out that the mouth also undergoes continuous colonization, presenting a vast microbiota. In it, there is almost half of the microbiota present in the human body, represented by various species of bacteria, fungi and viruses.

In children, cariogenic microorganisms play an important role in the evolution of caries. Vertical transmission of microorganisms occurs via saliva, mainly mothers or caregivers with high levels of Streptococcus mutans, contaminating children early and increasing prevalence of caries. During hospitalization, how children are completely dependent on the professional team and the family or accompanying person, such care should be doubled in such a way that the contamination is avoided.

Some measures may be incorporated by the dentist into the hospital routine, so that the oral health of the infant patient is maintained:

- Oral hygiene should be incorporated into the routine of the hospital, in the same importance as playing, bathing and feed.

- The motivation of family members and children should be promoted by through recreational activities.

- $\quad$ Apply saline or moisturizing to the lips.

- Apply dental gel, with or without fluoride, with moistened toothbrush.

- Brush your teeth to the child's age. The preference between brush or toe should be at the discretion of the professional, assessing the condition of each child. Hygiene should be done every 12 hours.

- Irrigate the clean area with water and vacuum before proceeding with cleaning from the next quadrant.
These measures do not free the patient from the risks, as they displace fixed microorganisms on the dental plaque. Once free of adhesion, they can be driven by trachea in case are not vacuumed correctly. Topical administration of a bactericidal agent, chlorhexidine digluconate at $0.12 \%$, does not significantly alter the presence of microorganisms, however, there is a large reduction in the number of bacteria in the oropharynx in children.

Children hospitalized in the oncology sectors present, due to oral care recommended in patients undergoing chemotherapy, reduction of oral mucositis and ulcerative lesions induced by chemotherapy. In the case of intubated patients, there are brushes adapted to suction systems that allow removal and suction dental plaque simultaneously. In intubated children, mouth openers, silicon rubbers should be used to support the upper and lower arch, facilitating access. Toothpaste Care should also be recommended, excessive amount of foam can generate sensation of asphyxiation in the patient, so the amount of cream should be controlled.

The cream should be fluoridated and it is necessary to avoid ingestion so that fluorosis does not occur permanent teeth. The application of fluoridated varnish is indicated only once in the period of hospitalization and may be repeated again after 3 months. The child's routine in relation to feeding undergoes changes in habits and schedules, medicines are often introduced at these times. They are often biscuits, biscuits and sweets into the food, however, the risk of periodontal and caries increases without a hygiene. The plate increase also will considerably increase the risk of systemic infections and, therefore, prevention is so important.

The family should be sensitized and motivated to maintain the oral health of the child, as after the hospitalization period, care should be continued in the home. This therefore, teaching on prevention should be as important as the clinical care [7-14].

\section{Final Considerations}

The childish imaginary doesn't match the fact that it's sick. However, a enormity of children experiences the hospital reality from an early age. Fits to the dentist, within his or her performance, to minimize the side effects in the oral cavity. 
The intervention of the dentist should be complete, respecting the limits of each pathology, guiding oral hygiene and the adoption of a diet less cariogenic. It is important to carry out elective and urgent procedures, always in tune with the medical team, with the aim of improving the quality of children's lives.

\section{Bibliography}

1. Sousa LC., et al. "O brincar no contexto hospitalar na visão dos acompanhantes de crianças internadas". Journal of Human Growth and Development 25 (2015): 41-49.

2. Elias A. "Ressignificação da dor simbólica da morte: relaxamento mental, imagens mentais e espiritualidade". Psicologia Ciência e Profissão 21.3 (2003): 92-97.

3. Barros FC and Victoria CG. "Maternal-child health in Pelotas, Rio Grande do Sul State, Brazil: major conclusions from comparisons of the 1982, 1993, and 2004 birth cohorts". Cadernos de Saúde Pública Rio de Janeiro 24.3 (2008).

4. Vasques RCY., et al. "A experiência de sofrimento: histórias narradas pela criança hospitalizada". Revista da Escola de Enfermagem 45.1 (2011): 122-129.

5. Dickerman JD. "The late effects of childhood cancer therapy". Pediatrics 119.3 (2007): 554-568.

6. Rabelo GD., et al. "Atendimento Odontológico ao paciente em unidade de terapia intensive". Arquivos Médicos dos Hospitais e da Faculdade de Ciências Médicas da Santa Casa de São Paulo 55.2 (2010): 67-70.

7. Araújo JE. "Pacientes Pediátricos em regime de internação hospitalar : Riscos de Patologias bucais e métodos Preventivos". Revista Ciências e Odontologia 4.2 (2020): 9-16.

8. Conselho Federal De Odontologia. "Código de Ética Odontológico”. Brasília, Cap. XI, Artigo 26 (2012).

9. Da Silva Junior and Adilson Carlos. "Higiene oral: atuação da equipa de enfermagem em ambiente hospitalar". Revista de Enfermagem Referência (2020): 1.

10. De Araújo Alencar and Aréli Morais. "Condição bucal de pacientes internados em unidade de terapia intensiva pediátrica". Brazilian Journal of Health Review 3.4 (2020): 10127-10142.
11. Díaz-Ortiz ML., et al. "Dental health In liver transplant patients". Medicina Oral, Patologia Oral, Cirugia Bucal 10.1 (2005): 66-76.

12. Jorge WA. “Odontologia Hospitalar: bucomaxilofacial, urgências odontológicas eprimeiros socorros". Rio de Janeiro: Medbook (2009).

13. Morais TM and Silva A. "Fundamentos da Odontologia em Ambiente Hospitalar/UTI". 1. edition. Rio de Janeiro: Elsevier (2015): 315-333.

14. Ribeiro Eliane de Oliveira Aranha, et al. "Atenção odontológica hospitalar às crianças internadas no ICAM (Instituto da Criança do Amazonas)". Extensão em Revista 1.1 (2017): 38-42.

\section{Assets from publication with us}

- Prompt Acknowledgement after receiving the article

- Thorough Double blinded peer review

- Rapid Publication

- Issue of Publication Certificate

- High visibility of your Published work

Website: www.actascientific.com/

Submit Article: www.actascientific.com/submission.php

Email us: editor@actascientific.com

Contact uS: +919182824667 